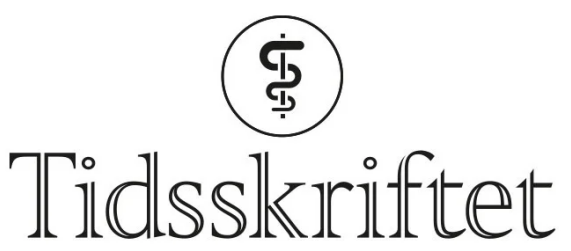

DEN NORSKE LEGEFORENING

\title{
Vedvarende bruk av opioider og samtidig bruk av andre vanedannende legemidler
}

ORIGINALARTIKKEL

\section{INGVILD ODSBU}

ingvild.odsbu@fhi.no

Avdeling for psykiske lidelser

Folkehelseinstituttet

Hun har bidratt med idé, tolking av data, utarbeiding og godkjenning av manuskriptet.

Ingvild Odsbu er seniorforsker.

Forfatteren har fylt ut ICMJE-skjemaet og oppgir ingen interessekonflikter.

\section{MARTE HANDAL}

Avdeling for kroniske sykdommer

Folkehelseinstituttet

og

Senter for rus- og avhengighetsforskning (SERAF)

Institutt for klinisk medisin

Universitetet i Oslo

Hun har bidratt med idé, tolking av data, utarbeiding og godkjenning av manuskriptet.

Marte Handal er avdelingsdirektør og spesialist i klinisk farmakologi.

Forfatteren har fylt ut ICMJE-skjemaet og oppgir ingen interessekonflikter.

\section{VIDAR HJELLVIK}

Avdeling for kroniske sykdommer

Folkehelseinstituttet

Han har bidratt med analyse, tolking av data og godkjenning av manuskriptet.

Vidar Hjellvik er seniorforsker.

Forfatteren har fylt ut ICMJE-skjemaet og oppgir ingen interessekonflikter.

\section{PETTER C. BORCHGREVINK}

Avdeling for smerte og sammensatte lidelser

St. Olavs hospital

og

Institutt for sirkulasjon og bildediagnostikk

NTNU

Han har bidratt med idé, tolking av data og godkjenning av manuskriptet.

Petter C. Borchgrevink er avdelingssjef, overlege og professor.

Forfatteren har fylt ut ICMJE-skjemaet og oppgir ingen interessekonflikter.

THOMAS CLAUSEN

Senter for rus- og avhengighetsforskning (SERAF)

Institutt for klinisk medisin

Universitetet i Oslo

Han har bidratt med idé, tolking av data og godkjenning av manuskriptet.

Thomas Clausen er senterleder og professor.

Forfatteren har fylt ut ICMJE-skjemaet og oppgir ingen interessekonflikter.

Han har bidratt med idé, tolking av data og godkjenning av manuskriptet.

Ragnar Nesvåg er spesialist i psykiatri og avdelingsdirektør.

Forfatteren har fylt ut ICMJE-skjemaet og oppgir ingen interessekonflikter. 


\section{BAKGRUNN}

Vedvarende bruk av opioider kan ha uheldige konsekvenser. Vi har undersøkt vedvarende opioidbruk i pasientgrupper som fikk forskrevet opioider på ulike indikasjoner (langvarig smerte, palliativ behandling, andre (hvit resept)), samt gruppenes samtidige bruk av enkelte andre vanedannende legemidler.

MATERIALE OG METODE

Personer med minst én utlevering av et opioid i Reseptregisteret i perioden 2011-19 ble inkludert. Vedvarende bruk $i$ et kalenderår ble definert som uthenting av $>180$ definerte døgndoser eller $>4500 \mathrm{mg}$ orale morfinekvivalenter fordelt på minst tre kvartaler.

\section{RESULTATER}

Antall vedvarende opioidbrukere var 50422 i 2011 og 59996 i 2019 (10,1\% og 10,7\% av alle opioidbrukere). I perioden $\emptyset$ kte antallet som fikk opioider på blå resept for langvarige smerter, med 9952 personer, men flertallet ( $n=38$ oo6, 63,3\%) fikk fortsatt utlevert opioider utelukkende på hvit resept i 2019. Henholdsvis 15623 (41,1\%) og 14881 (39,2 \%) av de vedvarende opioidbrukerne som fikk utlevert opioider kun på hvit resept i 2019, fikk også utlevert benzodiazepiner og z-hypnotika samme år. Av de 23967 vedvarende brukerne som også fikk utlevert benzodiazepiner, fikk 88 \% utlevert opioider og benzodiazepiner på samme dag minst én gang i løpet av 2019 .

\section{FORTOLKNING}

Vedvarende forskrivning av opioider på hvit resept og samtidig forskrivning av andre vanedannende legemidler kan tyde på uheldig bruk uten klar indikasjon.

\section{HOVEDFUNN}

Rundt $11 \%$ av opioidbrukerne i 2019 hadde vedvarende bruk.

De fleste med vedvarende bruk fikk forskrevet opioider utelukkende på hvit resept (63\% i 2019), fulgt av langvarige smertepasienter som fikk opioider på blå resept (24\%) og personer i palliativ behandling (12\%).

Det var høy forekomst av samtidig bruk av benzodiazepiner (> $34 \%$ ) og z-hypnotika (>35\%) blant vedvarende opioidbrukere.

Blant vedvarende opioidbrukere som også fikk utlevert benzodiazepiner, fikk 88 \% utlevert opioider og benzodiazepiner på samme dag minst én gang i løpet av 2019.

Bruk av opioider for langvarige, moderate til sterke smerter kan være hensiktsmessig på kort sikt, men kan ofte ha betydelige negative konsekvenser for både individet og samfunnet på lang sikt. Vi mangler et robust og entydig kunnskapsgrunnlag som viser at opioider har god smertelindrende effekt ved langvarig behandling (1). Negative konsekvenser knyttet til langvarig bruk er blant annet risiko for opioidindusert hyperalgesi, overdose og avhengighetsutvikling ( $(\underline{2}-5)$. I Norge har det de siste årene vært en $\emptyset \mathrm{kning} \mathrm{i}$ andelen overdosedødsfall som skyldes reseptbelagte opioider uten tilstedeværelse av illegale rusmidler i blodet (므).

Opioider forskrives ved moderate til sterke smerter og har tradisjonelt blitt brukt til å behandle akutte smerter av ulike typer, som for eksempel postoperativ smerte eller etter skader. I slike situasjoner forskrives opioider på hvit resept. I 2008 ble det gjort endringer i blåreseptordningen slik at pasienter med langvarige smerter, betydelig nedsatt livskvalitet og funksjonsevne kunne få smertestillende legemidler, deriblant opioider, på blå resept (7.). Fra 2016 ble fastlegene inkludert i ordningen, som gjelder for behandling av alle typer langvarige smerter og ikke er begrenset til spesifikke diagnoser. Forskriver må søke om individuelt vedtak for den enkelte pasient. Søknadsprosessen har blitt vesentlig forenklet de senere årene ved at man kan søke elektronisk og få bekreftet godkjennelse med én gang. Opioider kan også forskrives på blå resept som del av palliativ behandling. 
Vi har tidligere vist at antall personer som fikk opioider på blå resept for behandling av langvarige smerter, økte i perioden 2009-19 (ㅁ․,9), og at rundt halvparten av dem som inngikk i refusjonsordningen i 2009 fremdeles fikk utlevert opioider på blå resept ni år senere (9.). For i overkant av ti år siden ble det estimert at

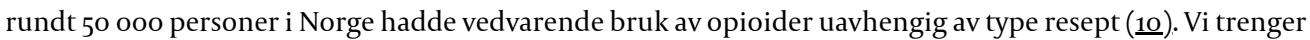
kunnskap om hvordan dette har utviklet seg og hvordan pasienter med vedvarende opioidbruk fordeler seg mellom ulike pasientgrupper som får forskrevet opioider.

Samtidig bruk av opioider og andre vanedannende legemidler (for eksempel benzodiazepiner) kan forsterke og forverre negative effekter av opioidbruk, som forsterket sedasjon og fare for respirasjonsstans og død. Ifølge nasjonal veileder for opioider bør man hos pasienter som starter langvarig opioidbehandling seponere andre vanedannende legemidler som benzodiazepiner og benzodiazepinlignende legemidler (z-hypnotika) (3). Det er imidlertid en høyere forekomst av angst og søvnproblemer hos pasienter med smerter sammenlignet med den generelle populasjonen. Det kan derfor være behov for samtidig legemiddelbehandling av smerter, angst og søvnproblemer hos denne pasientgruppen (11-13). Gitt den betydelig økte faren for alvorlige konsekvenser ved samtidig bruk bør det heller vurderes å seponere opioider dersom man skal starte behandling med andre vanedannende legemidler, alternativt behandle komorbide lidelser med ikke-vanedannende legemidler. Det er også viktig å utnytte den økende kunnskapen og tilfanget av ikke-opioide smertestillende midler i såkalt multimodal ikke-opioidbasert behandling av langvarige smerter.

I denne studien har vi undersøkt 1) utvikling i antall og andel personer med vedvarende bruk av opioider i perioden 2011-19, 2) antall og andel med vedvarende bruk av opioider for reseptkategoriene hvit resept, blå resept for behandling av langvarige smerter og blå resept for palliativ behandling i 2011, 2015 og 2019 og 3 ) samtidig bruk av andre vanedannende legemidler hos vedvarende opioidbrukere i de ulike reseptkategoriene i 2019 .

\section{Materiale og metode}

Reseptregisteret inneholder informasjon om alle legemidler som er forskrevet og utlevert til pasienter utenfor institusjon. I data fra Reseptregisteret er det mulig å skille mellom forskrivninger på blå og hvit resept. For blå resepter har vi informasjon om indikasjon for forskrivning. Legemiddelverket har opprettet egne refusjonskoder for indikasjonene langvarige smerter (-71) og palliativ behandling (-90)(7.). Det kan også forekomme registrering av opioider på blå resept med andre diagnosekoder $(<1 \%)$, selv om det bare er refusjonskodene -71 og-9o som skal benyttes. I Reseptregisteret registreres utlevert legemiddelmengde i antall definerte døgndoser (DDD) (14.). Vi har beregnet hva en opioidmengde angitt i antall DDD tilsvarer i milligram orale morfinekvivalenter (OMEQ) (15).

STUDIEPERIODE OG STUDIEPOPULASJON

Data fra perioden 2011-19 ble benyttet. Studiepopulasjonen bestod av alle individer som hadde minst én utlevering av et opioid (anatomisk, terapeutisk og kjemisk (ATC) kode No2A) i studieperioden. Opioider i ATCgruppene No7BC (opioider ved opioidavhengighet) og Ro5DA (hostedempende) ble ikke inkludert.

BRUKERE AV OPIOIDER ETTER RESEPTKATEGORI

Brukere av opioider et gitt år ble klassifisert i fire gjensidig utelukkende grupper i henhold til reseptkategori. Reseptkategoriene ble ordnet hierarkisk i følgende rekkefølge: palliativ behandling (blå resept, refusjonskode -9o), langvarige smerter (blå resept, refusjonskode -71), andre diagnosekoder (blå resept, andre diagnosekoder) og hvit resept. Inndelingen innebærer for eksempel at dersom et individ hadde minst én utlevering av et opioid på blå resept for palliativ behandling det aktuelle året, ble vedkommende klassifisert i kategorien palliativ behandling uavhengig av om vedkommende også hadde utleveringer av opioider innenfor de andre kategoriene samme år.

VEDVARENDE BRUK AV OPIOIDER

For å studere vedvarende bruk tok vi utgangspunkt i en metode utarbeidet av Svendsen og medarbeidere (2012) basert på «behandlingsintensitet» målt som antall DDD eller milligram OMEQ utlevert per kalenderår og «distribusjon» målt som antall kvartaler med utleveringer per år $(\underline{10})$. Kriteriene som måtte oppfylles for vedvarende bruk var > 18o DDD eller > 4500 mg OMEQ utlevert i løpet av året og utleveringer i minst tre kvartaler det aktuelle kalenderåret. Definisjonen av vedvarende bruk tilsvarer bruk av opioider tilsvarende minst 25 mg OMEQ per dag eller 1 DDD per dag minst halve året (for eksempel 4-16 tabletter kodein/paracetamol daglig minst halve året). 1 DDD kodein/paracetamol tilsvarer fire tabletter á zo mg kodein. Dette vil igjen tilsvare $6 \mathrm{mg}$ OMEQ.

Når man ser på «svake» og «sterke» opioider sammen, trenger man både DDD- og OMEQ-kravet for å fange opp høyt forbruk (16). Her er to eksempler:

Kodein/paracetamol (svakt opioid): $1 \mathrm{DDD}=120 \mathrm{mg}$ kodein, som tilsvarer $0,05 \times 120=6 \mathrm{mg}$ OMEQ (ved bruk av Helfos tabell for omregning (15)). 1 DDD daglig minst halve året er å anse som vedvarende høyt forbruk, men $6 \mathrm{mg}$ OMEQ er langt fra kravet om minst $25 \mathrm{mg}$ OMEQ. Her trenger vi DDD-kravet for å fange opp høyt forbruk.

Oksykodon (sterkt opioid): 1 DDD = $75 \mathrm{mg}$, tilsvarer 1,6 × $75=120 \mathrm{mg}$ OMEQ. Daglig dose på 20-40 mg (anbefalt startdose) minst halve året er å anse som vedvarende høyt forbruk, men tilfredsstiller ikke kravet til 1 DDD.

Derimot tilfredsstiller det med god margin kravet til 25 mg OMEQ. Her trenger man OMEQ-kravet for å fange opp høyt forbruk. 
Andelen (\%) vedvarende opioidbrukere ble beregnet som antall vedvarende opioidbrukere per 100 opioidbrukere det aktuelle året og som andel (\%) vedvarende opioidbrukere per 100 innbyggere det aktuelle året. Befolkningsgrunnlaget hvert år var middelbefolkningen (gjennomsnittet av befolkningen 1. januar og 31. desember) det aktuelle året, hentet fra Statistisk sentralbyrå. 95 \% konfidensintervall for andelene ble beregnet som

$$
p \pm 1.96 \sqrt{\mathrm{p}(1-\mathrm{p}) / N} \operatorname{der} p=\text { andel brukere og } N=\text { befolkningsstørrelsen. }
$$

\section{SAMTIDIG BRUK AV ANDRE VANEDANNENDE LEGEMIDLER I 2019}

For 2019 beregnet vi andelen av vedvarende opioidbrukere i de ulike reseptkategoriene som fikk utlevert minst ett annet vanedannende legemiddel (benzodiazepiner, z-hypnotika, pregabalin, gabapentin eller ADHD-legemidler) i løpet av året. Blant vedvarende opioidbrukere som fikk utlevert minst ett benzodiazepin i 2019, beregnet vi også andelen som fikk utlevert opioider og benzodiazepiner (i) på samme dag, (ii) innenfor 1-30 dager og (iii) med mer enn zo dagers avstand fordelt på de ulike reseptkategoriene. Kategoriene var gjensidig utelukkende og ble rangert hierarkisk i nevnte rekkefølge.

ETISKE OVERVEIELSER

Studien er godkjent av Regional komité for medisinsk og helsefaglig forskningsetikk (REK Sør-Øst 2019/298).

\section{Resultater}

I 2019 hentet 561917 personer ut minst én resept på opioider, og 59996 personer tilfredsstilte kriteriene for vedvarende bruk, mot 497462 og 50422 personer i 2011 (tabell 1). Blant personer med vedvarende bruk i 2019 var det 38322 kvinner (63,9\%) og 21674 menn (36,1\%). Andelen personer med vedvarende bruk av opioider varierte mellom 10,0 \% og 10,7 \% i perioden. Sett i forhold til hele befolkningen var andelen vedvarende opioidbrukere i 2011 1,02 \% (95\% konfidensintervall (KI) 1,01 til 1,03) og i 2019 1,12 \% (95\% KI 1,11 til 1,13). Andelen vedvarende opioidbrukere økte med alderen (tabell 1). I aldersgruppen 70 år og eldre var andelen vedvarende opioidbrukere 14,3\% (95\% KI 14,1 til 14,5) i 2011 og 15,7\% (95\% KI 15,5 til 15,9) i 2019, mens andelene i de yngre aldersgruppene holdt seg relativt stabile i samme periode. Aldersfordelingen i gruppen 70 år og eldre var stabil gjennom perioden (gjennomsnittlig alder var 81,o år i 2011 og 8o,8 år i 2019).

\section{Tabell 1}

Antall og andel (\%) med vedvarende bruk av opioider fordelt på aldersgrupper og totalt blant alle opioidbrukere, samt totalt i hele befolkningen i perioden 2011-19.

\begin{tabular}{|c|c|c|c|c|c|c|c|c|c|}
\hline & 2011 & 2012 & 2013 & 2014 & 2015 & 2016 & 2017 & 2018 & 2019 \\
\hline \multicolumn{10}{|l|}{$<18$ år } \\
\hline $\begin{array}{l}\text { Totalt antall } \\
\text { opioidbrukere }\end{array}$ & 6458 & 6841 & 6865 & 6855 & 6514 & 6510 & 6385 & 6147 & 6170 \\
\hline $\begin{array}{l}\text { Antall med } \\
\text { vedvarende } \\
\text { bruk }\end{array}$ & 14 & 17 & 20 & 16 & 15 & 19 & 18 & 9 & 10 \\
\hline $\begin{array}{l}\text { Andel med } \\
\text { vedvarende } \\
\text { bruk }\end{array}$ & 0,2 & 0,2 & 0,3 & 0,2 & 0,2 & 0,3 & 0,3 & 0,1 & 0,2 \\
\hline \multicolumn{10}{|l|}{ 18-44 år } \\
\hline $\begin{array}{l}\text { Totalt antall } \\
\text { opioidbrukere }\end{array}$ & 160543 & 164755 & 169099 & 171338 & 172895 & 174785 & 176096 & 174022 & 172675 \\
\hline $\begin{array}{l}\text { Antall med } \\
\text { vedvarende } \\
\text { bruk }\end{array}$ & 8400 & 8278 & 8267 & 8420 & 8642 & 8725 & 8653 & 8582 & 8446 \\
\hline $\begin{array}{l}\text { Andel med } \\
\text { vedvarende } \\
\text { bruk }\end{array}$ & 5,2 & 5,0 & 4,9 & 4,9 & 5,0 & 5,0 & 4,9 & 4,9 & 4,9 \\
\hline \multicolumn{10}{|l|}{ 45-69 år } \\
\hline $\begin{array}{l}\text { Totalt antall } \\
\text { opioidbrukere }\end{array}$ & 221015 & 228757 & 236612 & 242089 & 248741 & 251421 & 251733 & 249739 & 250406 \\
\hline
\end{tabular}




\begin{tabular}{|c|c|c|c|c|c|c|c|c|c|}
\hline & 2011 & 2012 & 2013 & 2014 & 2015 & 2016 & 2017 & 2018 & 2019 \\
\hline $\begin{array}{l}\text { Antall med } \\
\text { vedvarende } \\
\text { bruk }\end{array}$ & 26400 & 26798 & 27504 & 28811 & 29410 & 29821 & 29695 & 29912 & 30673 \\
\hline $\begin{array}{l}\text { Andel med } \\
\text { vedvarende } \\
\text { bruk }\end{array}$ & 11,9 & 11,7 & 11,6 & 11,9 & 11,8 & 11,9 & 11,8 & 12,0 & 12,2 \\
\hline \multicolumn{10}{|l|}{$\geq 70$ år } \\
\hline $\begin{array}{l}\text { Totalt antall } \\
\text { opioidbrukere }\end{array}$ & 109446 & 110660 & 112807 & 117094 & 121876 & 126323 & 129008 & 130470 & 132666 \\
\hline $\begin{array}{l}\text { Antall med } \\
\text { vedvarende } \\
\text { bruk }\end{array}$ & 15608 & 15907 & 16537 & 17660 & 18461 & 19306 & 19991 & 20305 & 20867 \\
\hline $\begin{array}{l}\text { Andel med } \\
\text { vedvarende } \\
\text { bruk }\end{array}$ & 14,3 & 14,4 & 14,7 & 15,1 & 15,1 & 15,3 & 15,5 & 15,6 & 15,7 \\
\hline \multicolumn{10}{|l|}{$\begin{array}{l}\text { Totalt (alle } \\
\text { opioidbrukere) }\end{array}$} \\
\hline $\begin{array}{l}\text { Totalt antall } \\
\text { opioidbrukere }\end{array}$ & 497462 & 511013 & 525383 & 537376 & 550026 & 559039 & 563222 & 560378 & 561917 \\
\hline $\begin{array}{l}\text { Antall med } \\
\text { vedvarende } \\
\text { bruk }\end{array}$ & 50422 & 51000 & 52328 & 54907 & 56528 & 57871 & 58357 & 58808 & 59996 \\
\hline $\begin{array}{l}\text { Andel med } \\
\text { vedvarende } \\
\text { bruk }\end{array}$ & 10,1 & 10,0 & 10,0 & 10,2 & 10,3 & 10,4 & 10,4 & 10,5 & 10,7 \\
\hline \multicolumn{10}{|l|}{$\begin{array}{l}\text { Totalt (hele } \\
\text { befolkning) }\end{array}$} \\
\hline $\begin{array}{l}\text { Antall } \\
\text { personer }\end{array}$ & 4953088 & 5018573 & 5080166 & 5137429 & 5189894 & 5236151 & 5276968 & 5311916 & 5348849 \\
\hline $\begin{array}{l}\text { Antall med } \\
\text { vedvarende } \\
\text { bruk }\end{array}$ & 50422 & 51000 & 52328 & 54907 & 56528 & 57871 & 58357 & 58808 & 59996 \\
\hline $\begin{array}{l}\text { Andel med } \\
\text { vedvarende } \\
\text { bruk }\end{array}$ & 1,02 & 1,02 & 1,03 & 1,07 & 1,09 & 1,11 & 1,11 & 1,11 & 1,12 \\
\hline
\end{tabular}

Antall personer med vedvarende opioidbruk som fikk forskrevet opioider på blå resept for behandling av langvarige smerter var 4457 i 2011 og 14409 i 2019 ( $\varnothing$ kning på 9952 personer) (tabell 2). Blant vedvarende opioidbrukere i 2019 fikk 38 oo6 (63,3\%) utlevert opioider utelukkende på hvit resept.

\section{Tabell 2}

Antall og andel (\%) personer med vedvarende bruk av opioider fordelt på reseptkategori i 2011, 2015 og 2019.

\begin{tabular}{|c|c|c|c|c|c|}
\hline År & $\begin{array}{l}\text { Totalt } \\
\text { antall }\end{array}$ & Hvit resept & $\begin{array}{l}\text { Langvarig smerte } \\
\text { (blå) }\end{array}$ & $\begin{array}{l}\text { Palliativ } \\
\text { behandling(blå) }\end{array}$ & $\begin{array}{l}\text { Andre diagnosekoder } \\
\text { (blå) }\end{array}$ \\
\hline 2011 & 50422 & $39029(77,4)$ & $4457(8,8)$ & $6925(13,7)$ & $11(0,0)$ \\
\hline 2015 & 56528 & $42101(74,5)$ & $7520(13,3)$ & $6775(12,0)$ & $132(0,2)$ \\
\hline 2019 & 59996 & $38006(63,3)$ & $14409(24,0)$ & $7178(12,0)$ & $403(0,7)$ \\
\hline $\begin{array}{l}\text { Differanse } \\
\text { fra } 2011 \text { til } \\
2019\end{array}$ & +9574 & -1023 & +9952 & +253 & +392 \\
\hline
\end{tabular}


Tabell 3 viser bruk av andre vanedannende legemidler blant vedvarende opioidbrukere i 2019 fordelt på reseptkategori. Blant personer med vedvarende bruk som fikk utlevert opioider utelukkende på hvit resept, var forekomsten av bruk av benzodiazepiner og z-hypnotika henholdsvis 41,1\% og 39,2 \%. Tilsvarende andeler for vedvarende brukere som fikk opioider på blå resept for behandling av langvarige smerter, var 34,3\% og $35,7 \%$. Det var høyest forekomst av bruk av benzodiazepiner (45,9\%), z-hypnotika (46,4\%) og pregabalin $(16,6 \%)$ blant vedvarende opioidbrukere i palliasjonsgruppen.

\section{Tabell 3}

Antall og andel (\%) vedvarende opioidbrukere i 2019 med samtidig bruk (minst én utlevering i 2019) av andre vanedannende legemidler fordelt på reseptkategori (kategorien andre diagnosekoder (blå) er utelatt, n = 403)

\begin{tabular}{|c|c|c|c|}
\hline & $\begin{array}{l}\text { Hvite resepter }(n= \\
38 \text { oo6) }\end{array}$ & $\begin{array}{l}\text { Langvarige smerter } \\
\text { (blå) }(n=14409)\end{array}$ & $\begin{array}{l}\text { Palliativ behandling }(\text { blå })(n \\
=7178)\end{array}$ \\
\hline Benzodiazepiner & $15623(41,1)$ & $4939(34,3)$ & $3296(45,9)$ \\
\hline Z-hypnotika & $14881(39,2)$ & $5144(35,7)$ & $3331(46,4)$ \\
\hline Pregabalin & $2823(7,4)$ & $2109(14,6)$ & $1190(16,6)$ \\
\hline Gabapentin & $4694(12,4)$ & $2460(17,1)$ & $950(13,2)$ \\
\hline ADHD-legemidler & $748(1,7)$ & $255(1,8)$ & $32(0,4)$ \\
\hline
\end{tabular}

Av de 23967 vedvarende opioidbrukerne som fikk utlevert benzodiazepiner i 2019, fikk $88 \%$ begge deler utlevert på samme dag, mens henholdsvis $11,5 \%$ og o,5 \% fikk utlevert opioider og benzodiazepiner innenfor 1зо dager og med mer enn 30 dagers mellomrom.

\section{Diskusjon}

Hovedfunnene i denne studien var at rundt $11 \%$ av alle personer som fikk forskrevet opioider i 2019, hadde vedvarende opioidbruk. Denne andelen var stabil på 10-11 \% i perioden 2011-19, men antallet vedvarende brukere økte med rundt 9 6oo personer. Blant alle opioidbrukere var det høyest forekomst av vedvarende bruk blant personer som var 70 år eller eldre, og for denne aldersgruppen $\emptyset \mathrm{kte}$ andelen vedvarende brukere i perioden 2011-19, selv om aldersfordelingen i gruppen ikke endret seg. $\emptyset \mathrm{kningen} \mathrm{i} \mathrm{totalt} \mathrm{antall} \mathrm{vedvarende}$ brukere skyldtes tilsynelatende hovedsakelig at flere personer fikk utlevert opioider på blå resept for behandling av langvarige smerter. Likevel fikk flertallet av personer med vedvarende bruk forskrevet opioider utelukkende på hvit resept. Det var høy forekomst av samtidig bruk av andre vanedannende legemidler blant vedvarende opioidbrukere, og 88 \% av dem med både benzodiazepiner og opioider fikk disse utlevert på samme dag minst én gang i løpet av året.

I 2019 var det nær 6o ooo personer med en opioidbruk som ble definert som vedvarende. 6o ooo personer med vedvarende opioidbruk og en økning på rundt 9 6oo personer i løpet av en tiårsperiode kan virke lite i forhold til det totale antallet opioidbrukere (rundt 560 ooo personer i 2019), men for den enkelte pasient kan vedvarende bruk av opioider ha alvorlige konsekvenser. At det er en høy forekomst av vedvarende opioidbruk og en økning i andelen vedvarende opioidbrukere blant eldre, er spesielt bekymringsfullt, da konfusjon, svimmelhet og ustøhet som følge av opioidbruk oftest forekommer hos eldre.

Blant de nær 6o ooo vedvarende opioidbrukerne i 2019 fikk over 6o \% utlevert opioider på kun hvit resept. Dette var en overraskende stor andel, gitt at det finnes en refusjonsordning for opioidbehandling av langvarige, sterke smerter (7.). Fastlegene fikk muligheten til å forskrive opioider på blå resept for langvarige smerter først i 2016. Det ble observert en kraftig økning i antallet personer som inngikk i blåreseptordningen i perioden 2016-17 (ㅁ․9.). Antallet personer med vedvarende bruk av opioider på hvit resept har holdt seg stabilt høyt i perioden 2011-19, og det kan dermed tyde på at det er en gruppe pasienter som ikke oppfyller kravene til individuell refusjon og som dermed fortsetter å få forskrevet store mengder opioider på hvit resept, ofte også i kombinasjon med andre vanedannende legemidler.

I henhold til nasjonale veiledere bør ikke opioidbrukere ha samtidig bruk av andre vanedannende legemidler, som f.eks. benzodiazepiner eller z-hypnotika, over lengre tid $(3,4$.). På tross av dette var det høy forekomst av samtidig bruk av andre vanedannende legemidler blant vedvarende opioidbrukere. Pasienter i palliativ behandling hadde som forventet høyest forekomst av samtidig bruk av benzodiazepiner og z-hypnotika. Dette funnet er ikke så bekymringsfullt, da enkelte pasienter kan ha behov for medikamentell behandling av angst og søvnproblemer i livets sluttfase.

Blant vedvarende opioidbrukere som fikk opioider på hvit resept, var spesielt bruk av benzodiazepiner og zhypnotika vanlig. De fleste som fikk utlevert opioider og benzodiazepiner samme år, fikk begge legemiddelgrupper utlevert på samme dag minst én gang i løpet av året. Dette viser at opioider trolig brukes samtidig med andre vanedannende legemidler. Hos disse personene vil det kunne være fare for 
avhengighetsutvikling og alvorlige komplikasjoner som respirasjonsstans og død. Det var høy forekomst av bruk av pregabalin og gabapentin blant vedvarende opioidbrukere som fikk opioider utlevert på blå resept for langvarige smerter (henholdsvis 14,6\% og 17,1\%). Dette funnet er ikke så overraskende, da samtidig bruk av opioider og gabapentinoider kan være indisert ved uttalt nevropatisk smerte. Det er uvisst hvorvidt gabapentin er å anse som et vanedannende legemiddel på linje med pregabalin. Obduksjonsstatistikk viser at gabapentin i økende grad påvises ved rettsmedisinsk obduksjon, samtidig som bruken i befolkningen ikke har $ø$ kt i samme størrelsesorden (17.).

Et økende antall personer som bruker opioider vedvarende, vil sannsynligvis medføre at flere utvikler problematisk bruk og opioidavhengighet som kan få alvorlige konsekvenser. Her kan det nevnes at reseptpliktige opioider har vært den dominerende dødsårsaken blant overdosedødsfall i Norge de siste årene (6). Ved å kombinere flere vanedannende legemidler samtidig over tid kan risikoen for avhengighetsutvikling og andre alvorlige komplikasjoner $ø$ ke. Det er viktig at forskrivende leger nøye vurderer behovet og legger en klar behandlingsplan ved oppstart av smertebehandling med opioider for langvarig smerte. Andre medikamentelle og ikke-medikamentelle alternativer bør eksplisitt vurderes og helst utprøves.

\section{BEGRENSNINGER}

Vi har gått ut fra at dersom en person henter ut et legemiddel fra apotek, ble dette legemiddelet også brukt av personen. Det trenger ikke å være tilfellet, noe som innebærer at vi kan ha overestimert totalt antall brukere av de ulike legemidlene. Det er mindre sannsynlig at vedvarende opioidbrukere som henter ut opioider gjentatte ganger, ikke bruker legemiddelet.

Reseptregisteret inneholder opplysninger om legemidler som forskrives på resept og som utleveres fra apotek til pasienter utenfor institusjon. Legemidler pasienter får på sykehus eller sykehjem blir ikke registrert på individnivå i Reseptregisteret. Dette kan medføre underestimering av antallet og andelen legemiddelbrukere, særlig blant de eldste i befolkningen.

For å klassifisere personer som vedvarende opioidbrukere ble antall DDD og mengde OMEQ utlevert per kalenderår benyttet, og ikke for en periode på 365 dager, slik det tidligere er gjort i en studie av Svendsen og medarbeidere (10 $)$. Dette kan ha ført til en underestimering av antallet vedvarende opioidbrukere, spesielt for brukere som hadde en kort tid med vedvarende bruk og der denne tiden er fordelt på to år (f.eks. to kvartaler per år). Frikortordningen gjelder per kalenderår, og dette kan føre til en opphopning av utleverte blåresepter mot slutten av året. Internasjonalt eksisterer det flere ulike måter å definere vedvarende bruk på. I denne studien har vi valgt en metode basert på norske data med en forholdsvis streng definisjon av vedvarende opioidbruk. Valg av metode vil kunne påvirke resultatene.

Bruk av andre vanedannende legemidler ble definert som minst én utlevering av et annet vanedannende legemiddel i løpet av samme år. Vi vet ikke om legemidlene faktisk ble brukt samtidig. Pasienter som klassifiseres som vedvarende opioidbrukere etter vår definisjon, får utlevert opioider i mengder som mest sannsynlig tilsvarer et relativt høyt forbruk gjennom store deler av året. Det er derfor stor sannsynlighet for samtidig bruk i perioder. Analysene av utleveringer av opioider og benzodiazepiner på samme dag støtter oppunder dette.

KONKLUSJON

I perioden 2011-19 har antallet vedvarende opioidbrukere økt, mens andelen har holdt seg relativt stabil både i forhold til alle opioidbrukere og totalbefolkningen. Rundt $11 \%$ av opioidbrukerne hadde vedvarende høyt forbruk, og flertallet fikk opioider forskrevet utelukkende på hvit resept. Blant alle vedvarende opioidbrukere var det også en høy andel som fikk forskrevet andre vanedannende legemidler, også på samme dag, noe som indikerer problematisk bruk. Våre funn tyder på at en del opioidbehandling for langvarig smerte og samtidig behandling med andre vanedannende legemidler er i strid med gjeldende retningslinjer. Dette indikerer forskrivningspraksis med høy risiko for uønskede konsekvenser for pasientene. Den høyeste forekomsten av vedvarende opioidbruk var blant personer 70 år og eldre, og denne aldersgruppen er spesielt sårbar for alvorlige konsekvenser. En strengere praksis og bistand fra lege til pasient for å seponere andre vanedannende legemidler er viktig dersom langvarig opioidbehandling skal være forsvarlig.

Ingvild Odsbu, Vidar Hjellvik og Svetlana Skurtveit er delvis finansiert av Norges forskningsråd, prosjektnummer 320360 . Artikkelen er fagfellevurdert.

\section{LITTERATUR}

1. Chou R, Turner JA, Devine EB et al. The effectiveness and risks of long-term opioid therapy for chronic pain: a systematic review for a National Institutes of Health Pathways to Prevention Workshop. Ann Intern Med 2015; 162: 276-86. [PubMed] [CrossRef]

2. Els C, Jackson TD, Kunyk D et al. Adverse events associated with medium- and long-term use of opioids for chronic noncancer pain: an overview of Cochrane Reviews. Cochrane Database Syst Rev 2017; 10: Cdo12509. [PubMed]

3. Helsedirektoratet. Opioider. Nasjonal veileder. https://www.helsedirektoratet.no/veiledere/opioider Lest 21.6.2021. 
4. Helsedirektoratet. Vanedannende legemidler. Nasjonal veileder.

https://www.helsedirektoratet.no/veiledere/vanedannende-legemidler Lest 17.8.2021.

5. Samuelsen PJ, Nielsen CS, Wilsgaard T et al. Pain sensitivity and analgesic use among 10,486 adults: the Troms $\emptyset$ study. BMC Pharmacol Toxicol 2017; 18: 45. [PubMed][CrossRef]

6. Oslo universitetssykehus. Opioidrelaterte dødsfall 200o-2017. https://oslo-universitetssykehus.no/seksjon/avdeling-forrettsmedisinske-fag/Documents/Opioidrelaterte\%20d\%c3\%b8dsfall\%202000-2017.pdf Lest 24.6.2021.

7. Helfo. Individuell stønad til opioider. https://www.helfo.no/regelverk-og-takster/blareseptordningen-forhandsgodkjentog-individuell-stonad/blaresept-og-individuell-stonad/individuell-stonad-til-opioider/individuell-stonad-til-opioider Lest 21.6.2021.

8. Odsbu I, Handal M, Hjellvik V et al. Bruk av andre vanedannende legemidler blant opioidbrukere med langvarige smerter. Nor Epidemiol 2021; 29: 45-53. [CrossRef]

9. Skurtveit S, Hjellvik V, Sakshaug S et al. Forskrivning av opioider på blå resept mot langvarige smerter. Tidsskr Nor Legeforen 2020; 140. doi: 10.4045/tidsskr.20.0153. [PubMed][CrossRef]

10. Svendsen K, Skurtveit S, Romundstad P et al. Differential patterns of opioid use: defining persistent opioid use in a prescription database. Eur J Pain 2012; 16:359-69. [PubMed][CrossRef]

11. Mellbye A, Karlstad $\varnothing$, Skurtveit $S$ et al. Co-morbidity in persistent opioid users with chronic non-malignant pain in Norway. Eur J Pain 2014; 18:1083-93. [PubMed][CrossRef]

12. Nijs J, Mairesse O, Neu D et al. Sleep Disturbances in Chronic Pain: Neurobiology, Assessment, and Treatment in Physical Therapist Practice. Phys Ther 2018; 98:325-35. [PubMed][CrossRef]

13. van Hecke O, Torrance N, Smith BH. Chronic pain epidemiology and its clinical relevance. Br J Anaesth 2013; 111: 13-8. [PubMed][CrossRef]

14. WHO. Definition and general consideration. WHO Collaborating Centre for Drug Statistics Methodology. https://www.whocc.no/ddd/definition_and_general_considera/ Lest 17.8.2021.

15. Helfo. Morfinekvivalenter. http://www.helfoweb.com/morfinekvivalenter/ Lest 17.8.2021.

16. Svendsen K, Borchgrevink P, Fredheim O et al. Choosing the unit of measurement counts: the use of oral morphine equivalents in studies of opioid consumption is a useful addition to defined daily doses. Palliat Med 2011; $25: 725-32$. [PubMed][CrossRef]

17. Oslo universitetssykehus. Obduksjonsstatistikk: Funn i blodprøver fra obduksjoner utført i 202o. https:|/oslouniversitetssykehus.no/seksjon/avdeling-for-rettsmedisinske-

fag/Documents/Obduksjonsstatistikk\%20for\%202020_publiseres.pdf Lest 7.7.2021.

Publisert: 14. februar 2022. Tidsskr Nor Legeforen. DOI: 10.4045/tidsskr.21.0659

Mottatt 16.9.2021, første revisjon innsendt 17.11.2021, godkjent 20.12.2021.

Publisert under åpen tilgang CC BY-ND. Lastet ned fra tidsskriftet.no 26. april 2023. 